\title{
KEPADATAN POPULASI DAN NISBAH KELAMIN IKAN BUTUH KELENG (Butis butis) DI SUNGAI BELAWAN
}

\author{
Helentina Mariance Manullang1), Khairul 2*) \\ ${ }^{1)}$ Fakultas Perikanan, Universitas Dharmawangsa Medan, \\ ${ }^{2)}$ Fakultas Keguruan dan Ilmu Pendidikan, Universitas Labuhanbatu, \\ e-mail:khairulbiologi75@gmail.com
}

\begin{abstract}
Belawan River stores a fairly high diversity of fish, one of which is the crazy fish (Butis butis). A study of the bioecology of crazy fish has not done in Indonesia. They are considering the lack of bioecology of this fish in Indonesia. At the same time, bioecology data is needed by various parties as data and important information to know the condition of the fish population in nature. The purpose of this research is to know the population density and genital ratio of fish need keleng in Belawan River. This research is exploration. The location of fish sampling used a purposive sampling method. Fish arrested one time each month using a fishing rod. The collected fish are taken in total length and weight and identified the type of gender. Processing data using the application program Microsoft Excel 2010. The results showed the population density of fish at Station $1\left(0.91\right.$ individual $\left./ \mathrm{m}^{2}\right)$, Station $2\left(0.92\right.$ individual $/ \mathrm{m}^{2}$, and station $3\left(0.35\right.$ individual $\left./ \mathrm{m}^{2}\right)$. Sex ratio at Station 1 , male fish $(66 \%)$ and female (34\%), Station 2, male fish $(50,60 \%)$ and females $(49,40 \%)$ and Station 3, male $(50,77 \%)$ and females $(49,23 \%)$.
\end{abstract}

Keywords: Butis butis, population density, Sex Ratio, Belawan River

\begin{abstract}
Abstrak
Sungai Belawan menyimpan keanekaragaman ikan yang cukup tinggi, salah satunya adalah ikan butuh keleng (Butis butis). Kajian tentang bioekologi ikan butuh keleng belum ada yang melakukan di Indonesia. Mengingat, minim publikasi tentang bioekologi ikan ini di Indonesia. Padahal data bioekologi dibutuhkan berbagai pihak sebagai data serta informasi penting untuk mengetahui kondisi populasi ikan tersebut di alam. Tujuan penelitian ini adalah untuk mengetahui kepadatan populasi dan nisbah kelamin ikan butuh keleng di Sungai Belawan. Penelitian ini bersifat eksploratif. Penentuan stasiun pengamatan, untuk lokasi pengambilan sampel ikan dengan metode purposive sampling. Ikan ditangkap 1 kali dalam setiap bulannya menggunakan alat tangkap berupa pancing. Ikan yang dikoleksi diambil data panjang total dan beratnya, dan diidentifikasi jenis kelaminnya. Pengolahan data menggunakan aplikasi program Microsoft Excel 2010. Hasil penelitian menunjukan kepadatan populasi ikan pada Stasiun $1\left(0,91\right.$ individu $\left./ \mathrm{m}^{2}\right)$, Stasiun $2\left(0,92\right.$ individu $/ \mathrm{m}^{2}$, dan Stasiun $3(0,35$ individu $\left./ \mathrm{m}^{2}\right)$. Nisbah kelamin di Stasiun 1 ikan jantan $(66 \%)$ dan betina $(34 \%)$, Stasiun 2 ikan jantan $(50,60 \%)$ dan betina $(49,40 \%)$, dan Stasiun 3 ikan jantan $(50,77 \%)$ dan betina $(49,23 \%)$.
\end{abstract}

Kata Kunci: Butis butis, Kepadatan Populasi, Nisbah Kelamin, Sungai Belawan

\section{PENDAHULUAN}

Sungai Belawan merupakan perairan lenis yang berair payau. Muaranya menuju ke Selat Malaka, sehingga Sungai Belawan memiliki keanekaragaman jenis ikan yang cukup tinggi. Salah satu spesies ikan yang ditemukan di Sungai Belawan adalah Butis butis Hamilton, 1822. Nelayan sekitar menyebutnya sebagai ikan butuh keleng atau ikan gabus malas. Ikan ini merupakan penghuni tetap perairan ekosistem mangrove dan Sungai Belawan. Menurut ALA (2016) ikan butuh keleng (B. butis) lebih menyukai perairan yang 
bervegetasi dan sering ditemukan di rawa-rawa hutan mangrove. Ford et al, (2009) menjelaskan $B$. butis menghuni daerah pesisir, lingkungan payau seperti muara, laguna, dan hutan mangrove, tetapi juga diketahui mampu menembus sungai air tawar pasang surut sampai batas tertentu. Masyarakat yang berdomisili di sekitar Sungai Belawan memanfaatkan ikan ini sebagai ikan konsumsi saja, karena kurang mempunyai nilai ekonomis. Namun di beberapa daerah ikan ini dijadikan ikan hias, karena mempunyai perilaku yang unik dan harganya terbilang cukup mahal.

Menurut IUCN ikan butuh keleng (Crazy Fish/ Crimson Tipped Gudgeon) berdasarkan taksonominya dimasukan ke dalam: Kerajaan : Animalia, Filum : Chordata, Kelas : Actinoptherygii, Ordo : Perciformes, Famili : Eleotridae, Genus : Butis, Spesies : Butis butis. Menurut data tersebut saat ini statusnya kurang diperhatikan (Least Concern) (Larson dan Spark, 2017).

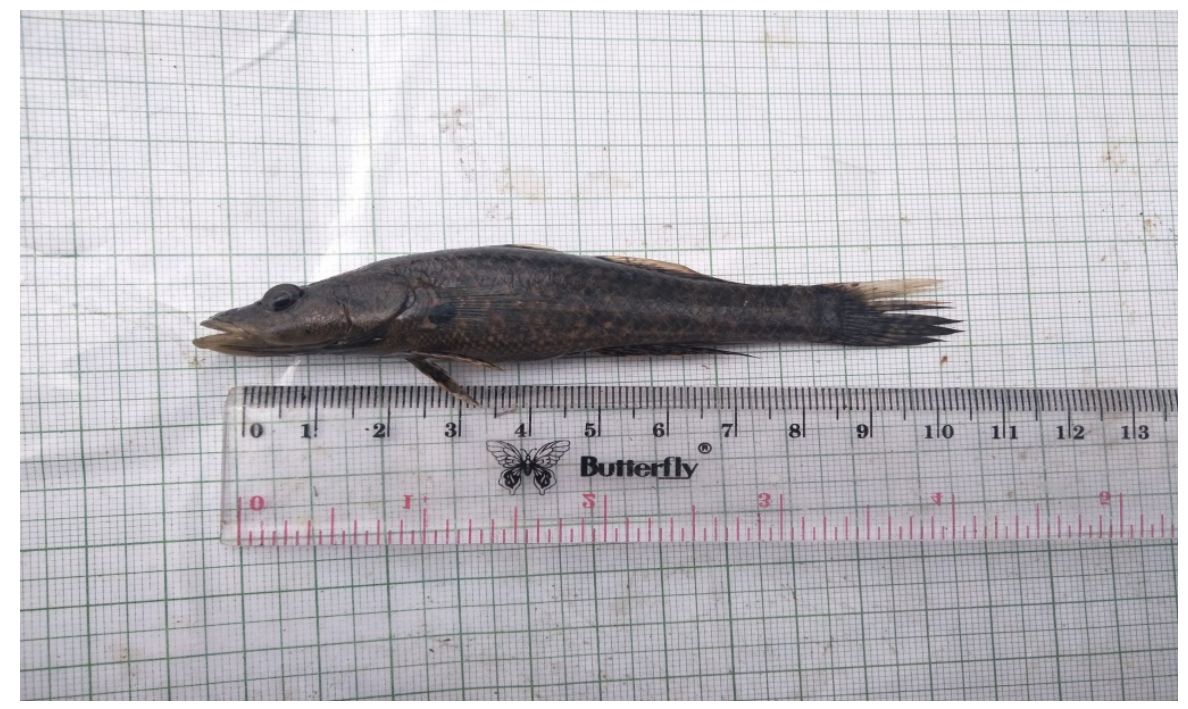

Gambar 1. Ikan Butuh Keleng (Butis butis)

Sumber: Dokumentasi Pribadi (2019)

Ikan butuh keleng masuk ke dalam kelompok ikan gobi (subclass: Gobiidae). Karakteristik yang sudah diketahui antara lain panjang tubuhnya berkisar antara $69-155$ $\mathrm{mm}$, memiliki garis memanjang gelap pada tubuh, sirip ekor hitam dengan pinggiran tipis pada bagian punggung, dasar dada dengan 1-2 bintik hitam (ALA, 2016). Karakteristik tubuh lainnya mempunyai rumus sirip Dorsal VIII,5, Anal VIII, dan Caudal 17. Ciri-ciri lain yang teramati adalah tipe mulut Superior, Sirip dorsal ganda terdiri dari jari-jari keras dan lunak, sirip caudal membulat dan tipe sisik ctenoid (Sari, 2016). Selanjutnya menurut Kottelat $d k k$ (1993) kepala pipih datar, lebar badan 4,5-5,0 kali lebih pendek dari Panjang Standar (Standard Length), 5-6 kali lebih pendek dari TL, mempunyai sisik-sisik tambahan, pipi dan moncong bersisik.

Tidak hanya sekedar mengenal diskripsinya saja, namun kita juga harus mengetahui peran ekologisnya. Secara ekologis ikan ini mempunyai peran penting, yakni pengendali nyamuk dan serangga. Hal ini dijelaskan oleh Probo (2014) makanan utamanya ikan B. butis adalah binatang hidup seperti udang renik, jentik-jentik nyamuk atau larva serangga lainnya, tetapi juga mau memakan bangkai binatang lainnya. Bila kelaparan ikan ini juga bisa memangsa anak-anak ikan lain bahkan anak-anaknya sendiri. Ikan ini termasuk ikan yang sangat rakus dan mampu memakan makanan seberat tubuhnya dalam sehari. Hasil penelitian Conchara $d k k$ (2018) menunjukkan bahwa ikan Gobiidae menempati beberapa posisi tingkat trofik yang berbeda dan memiliki peran ekologis yang penting di perairan Teluk Pabean. 
Penelitian tentang bioekologi ikan butuh keleng di Indonesia belum ada yang melakukan. Artikel publikasi tentang ikan ini pun sedikit sekali. Penelitian tentang kajian bioekologi perlu dilakukan, untuk mengetahui kondisi populasinya di alam. Kajian bioekologi diantaranya terkait kepadatan populasi dan nisbah kelamin. Data dan informasi mengenai kepadatan populasi dan nisbah kelamin dibutuhkan berbagai pihak terutama pemangku kebijakan, di dalam upaya pengelolaan sumber daya ikan butuh keleng agar bisa terjaga kelestariannya. Menurut Omar $d k k$ (2015) pengetahuan mengenai nisbah kelamin merupakan hal yang penting dan mendesak untuk dilakukan, dalam rangka menyediakan informasi dasar mengenai keseimbangan populasi dan ukuran ikan yang layak tangkap dari alam.

\section{METODE}

Penelitian dilaksanakan pada bulan Oktober, November, dan Desember 2019. Lokasi penelitian merupakan kawasan Sungai Belawan, Kelurahan Belawan Sicanang, Kecamatan Medan Belawan, Kota Medan, Provinsi Sumatera Utara. Peta lokasi penelitian dapat dilihat pada Gambar 2.

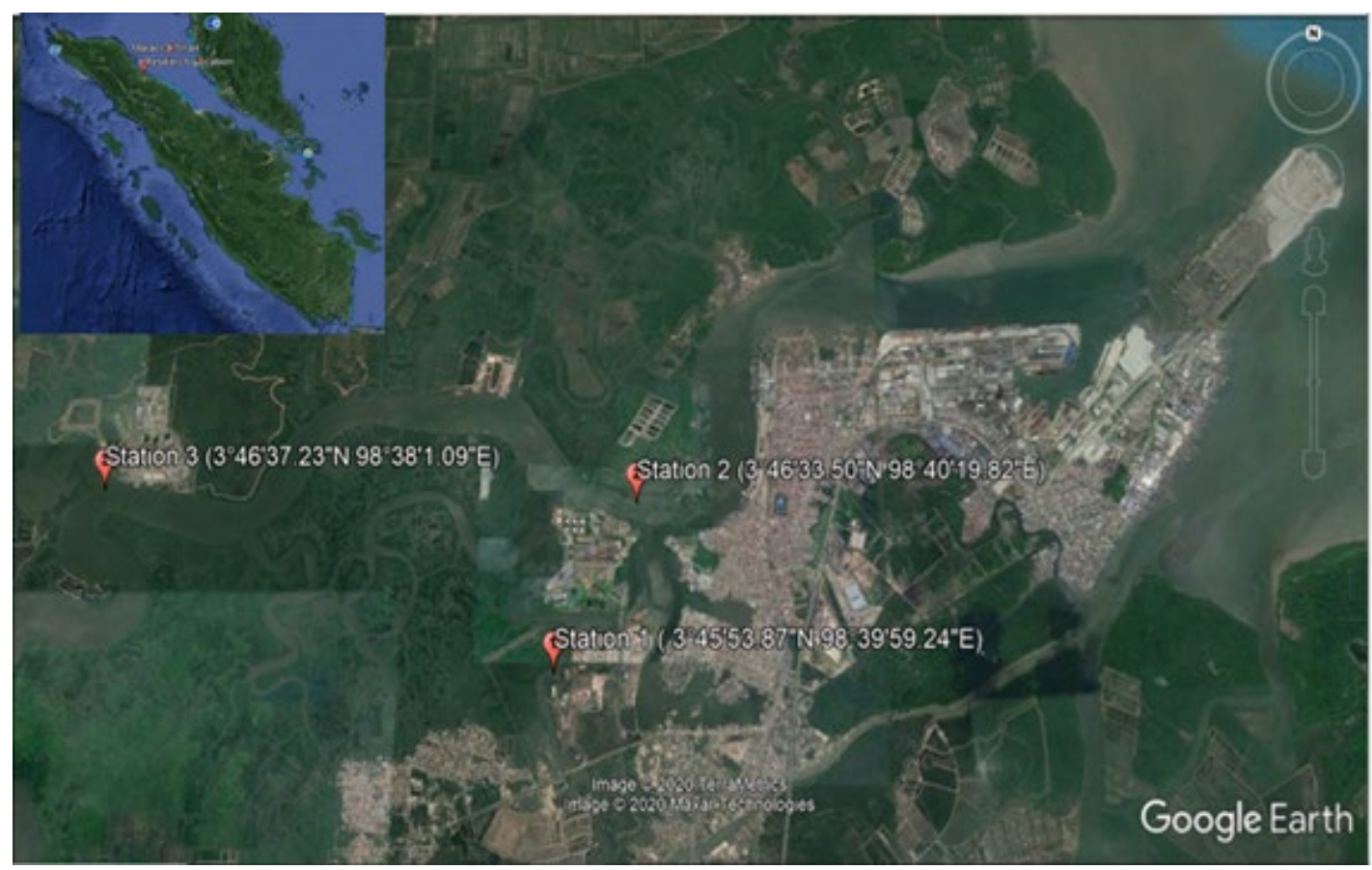

Gambar 2. Peta Lokasi Penelitian (Google Earth, 2019)

Kajian ini merupakan penelitian eksploratif. Penentuan stasiun pengamatan dengan teknik Puposive Sampling (ditentukan langsung oleh peneliti melalui pertimbangan dan informasi dari nelayan). Pengambilan sampel ikan dilakukan setiap bulan, yakni setiap tanggal 15 penanggalan bulan Hijriah mulai jam 08.00 sampai 12.00 WIB. Alat tangkap yang digunakan berupa kail/ pancing, dengan menggunakan umpan udang yang dikupas. Data penelitian yang dianalisis berupa:

\section{Kepadatan Populasi}

Kepadatan populasi ikan dihitung menggunakan rumus Kreb (1999):

$$
\mathrm{KP}\left(\text { Individu } / \mathrm{m}^{2}\right)=\frac{\text { Individu tertangkap }}{\text { Luas area penangkapan }}
$$




\section{Nisbah Kelamin}

Nisbah kelamin dapat dihitung dengan persamaan sebagai berikut (Effendie 2002):

$$
\mathrm{NK}=\frac{\mathrm{nJ}}{\mathrm{nB}}
$$

Keterangan: $\mathrm{NK}=$ Nisbah Kelamin, $\mathrm{nJ}=$ Jumlah Jantan, $\mathrm{nB}=$ Jumlah Betina

Ikan butuh keleng yang ditangkap hitung jumlahnya, kemudian diukur panjang totalnya dan berat timbang beratnya, serta diidentifikasi jenis kelaminnya. Pengolahan dan analisis data menggunakan aplikasi Microsoft Excel 2010.

\section{HASIL DAN PEMBAHASAN}

Kepadatan Populasi

Hasil analisa data terkait kepadatan populasi dapat dilihat pada Gambar 1 berikut:

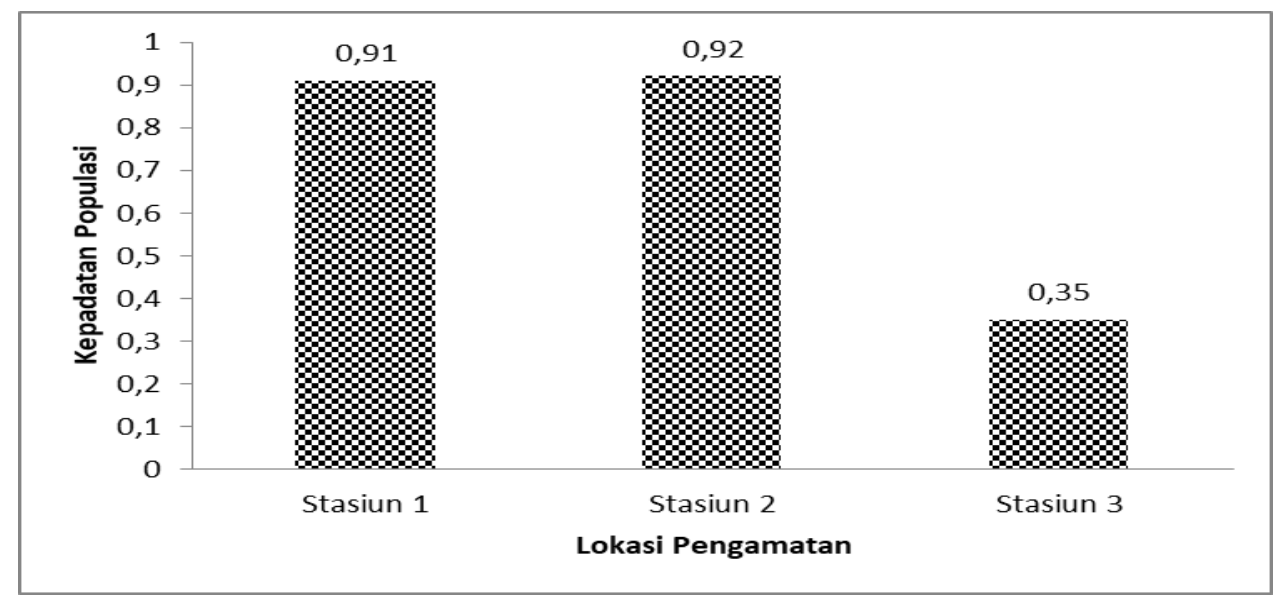

Gambar 3. Kepadatan Populasi Ikan Butuh Keleng Di Sungai Belawan

Berdasarkan hasil penelitian ini menunjukan kepadatan populasi ikan butuh keleng di Sungai Belawan cukup tinggi. Hal ini disebabkan kondisi ekosistem mangrove di Sungai Belawan masih cukup baik, sehingga kondisi ini masih baik untuk pertumbuhan maupun perkembangbiakannya. Hal ini didukung pendapat Sitorus et al (2017) kepadatan tanaman mangrove mampu meningkatkan keanekaragaman ikan. Hal Ini terkait dengan ketersediaan bahan organik dan detritus di ekosistem mangrove itu yang masuk ke perairan dan dimanfaatkan oleh organisme akuatik, termasuk ikan. Nilai kepadatan populasi ikan butuh keleng lebih tinggi dari hasil penelitian sebelumnya terhadap ikan keloso dan ikan garing.

Hasil penelitian Tjakrawidjaja dan Haryono (2001) terhadap kepadatan populasi ikan kaloso dikatakan masih cukup tinggi dengan kepadatan 0,017 ekor $/ \mathrm{m}^{2}$, dan pertambahan populasi sebanyak $0,0043 / \mathrm{m}^{2}$ per tahun. Selanjutnya hasil penelitian yang diperoleh Afrianti $d k k$ (2015) terhadap kepadatan populasi ikan gariang di Sungai Kambang Kecamatan Lenga yang Kabupaten Pesisir Selatan, dari sebanyak 37 ekor yang tertangkap diperoleh rata-rata kepadatan 0,0093 individu/ $\mathrm{m}^{2}$ ).

\section{Nisbah Kelamin}

Pada stasiun 1 ikan butuh keleng yang tertangkap sebanyak 12 individu, dari jumlah tersebut diperoleh jantan 8 individu (66\%) dan betina 4 ekor (34\%). Pada stasiun 2 ikan yang tertangkap berjumlah 14 individu dengan ikan jantan yang tertangkap sebanyak 9 individu $(59,40 \%)$ dan betina 5 individu (40,60\%). Pada stasiun 3 ikan tertangkap 7 individu dengan 
rincian ikan jantan sebanyak 3 individu (50,77\%), dan betina 4 individu (49,33\%). Data selengkapnya untuk masing-masing stasiun pengamatan dapat dilihat (Gambar 1.,2, dan 3)

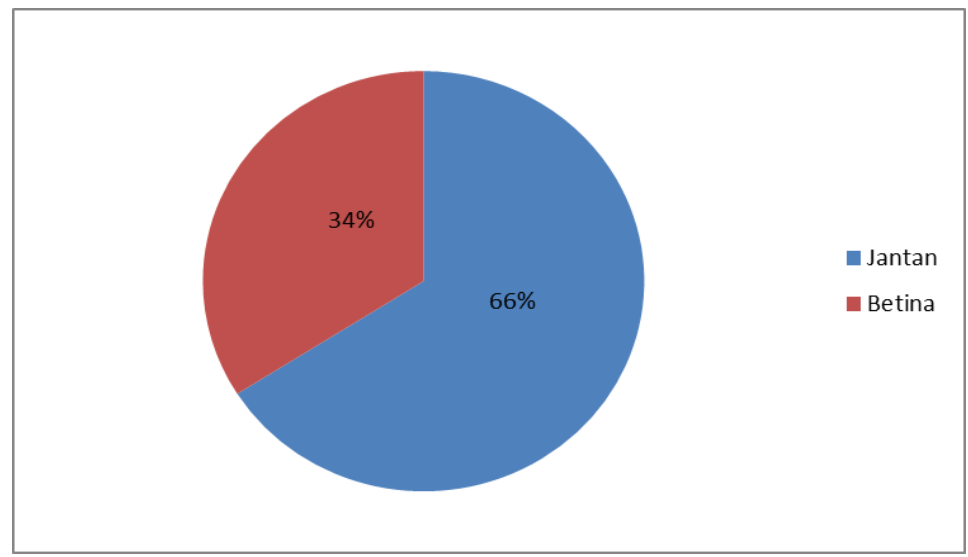

Gambar 4. Nisbah Kelamin Ikan Butuh Keleng Pada Stasiun 1

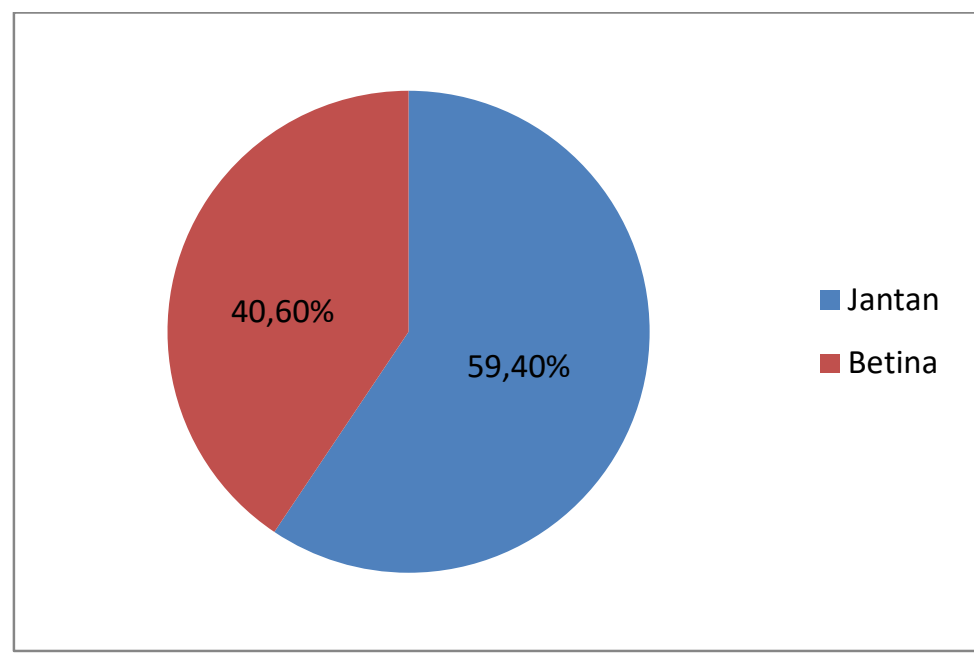

Gambar 5. Nisbah Kelamin Ikan Butuh Keleng Stasiun 2

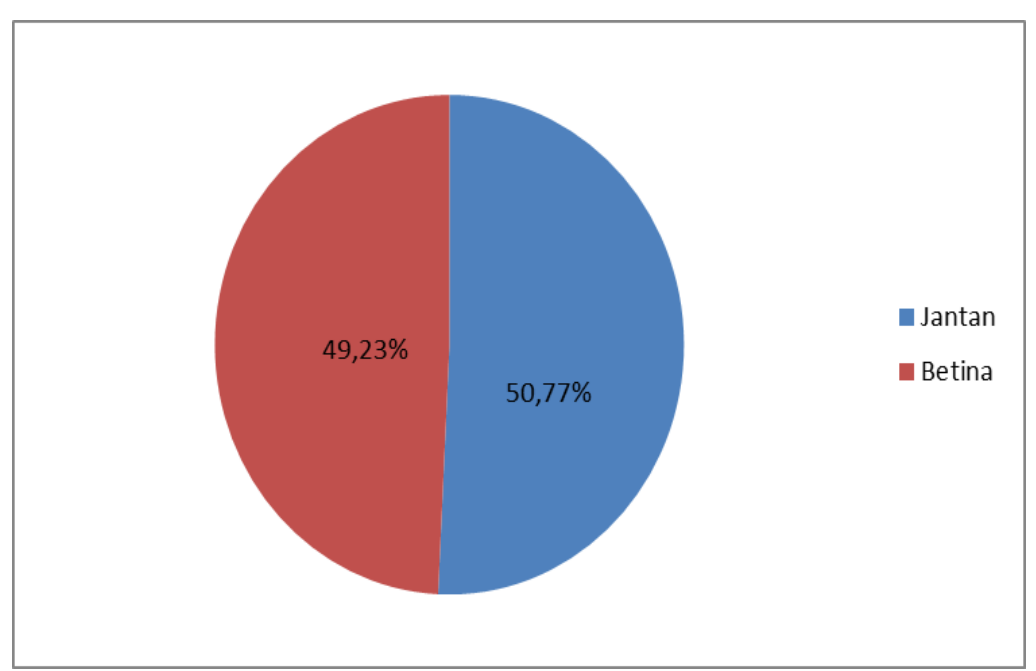

Gambar 6. Nisbah Kelamin Ikan Butuh Keleng Stasiun 3

Total jumlah ikan butuh keleng yang tertangkap selama penelitian sebanyak 33 individu, dengan rincian ikan jantan 20 individu dan betina 13 individu atau dengan perbandingan nisbah kelamin $60,60 \%$ dan $39,40 \%$. Perbandingan antara ikan jantan dan ikan 
betina tidak seimbang, karena musim pancaroba (peralihan musim penghujan ke musim kemarau). Nilai tersebut menunjukkan bahwa nisbah kelamin pada musim penghujan lebih seimbang dibandingkan musim kemarau. Kondisi ini diduga berkaitan dengan waktu pemijahan terutama dalam musim kemarau (Haryono $d k k, 2014$ ). Penelitian yang dilakukan oleh Dewantoro dkk (2019) pada ikan kebali (Osteochilus schlegelii) pada musim pancaroba lebih banyak mendapatkan ikan jantan. Menurut Persada (2016) jika dalam suatu perairan rasio ikan jantan lebih tinggi daripada ikan betina maka dapat menganggu kelestarian populasi. Hal ini dapat menyebabkan penurunan stok ikan di perairan yang akan menyebabkan kepunahan pada suatu populasi ikan.

\section{SIMPULAN}

Kepadatan populasi ikan butuh keleng masih cukup tinggi, diduga kondisi habitat ikan masih mendukung untuk pertumbuhan dan perkembangbiakan. Namun nisbah kelamin ikan butuh keleng antara jantan dengan betina berdasarkan Sungai Belawan tidak seimbang. Kondisi seperti ini dapat menyebabkan penurunan populasi bahkan bisa menyebabkan kepunahan di daerah kajian.

\section{DAFTAR PUSTAKA}

Afrianti, E., Nurhadi, \& Safitri, E. (2015). Kepadatan Populasi Ikan Gariang (Tor tambroides Blkr.) dan faktor fisika kimia perairan di Sungai Kambang Kecamatan Lengayang Kabupaten Pesisir Selatan. Jurnal Ilmiah Mahasiswa STKIP Sumatera Barat, 1-5.

ALA. (2016). Butis butis (Hamilton, 1822). Retrieved April 15, 2020, from ala.org.au: https://bie.ala.org.au/species/urn:lsid:biodiversity.org.au:afd.taxon:3352b01f-cf424937-8398-a7e9984d8836

Dewantoro, E., Yanto, H., Raharjo, E. I., \& Juniandy, A. L. (2019). Aspek Biologi Ikan kebali (Osteochilus schlegeii) Dari Sungai Kapuas Dan Sungai Sekayam Kalimantan Barat. Jurnal Ruaya, 1(1), 70-78.

Effendi, M. I. (2002). Biologi Perikanan. Yogyakarta: Yayasan Pustaka Nusantara.

Ford, M., Sitebe, A., \& Seriously Fish. (2009). Butis butis (HAMILTON, 1822). Retrieved April 15, 2020, from Seriously fish: https://www.seriouslyfish.com/species/butisbutis/

Haryono, Rahardjo, M. F., Mulyadi, \& Affandi, R. (2014). Pola Pertumbuhan dan Nisbah Kelamin Ikan Brek (Barbonymus balleroides Vall. 1842) pada Habitat yang Terfragmentasi di Sungai Serayu Jawa Tengah. Jurnal Biologi Indonesia, 10(2), 297305.

Khoncara, A. C., Sulistiono, Simanjuntak, C. P., Rahardjo, M. F., \& Zahid, A. (2018). Komposisi Makanan dan Strategi Makan Ikan Famili Gobiidae di Teluk Pabean, Indramayu. Jurnal Ilmu Pertanian Indonesia (JIPI), 23(2), 137-147.

Kottelat, M., Whitten, A. J., Kartikasari, S. N., \& Wirjoatmodjo, S. (1993). Freshwater Fish of Western Indonesian \& Sulawesi. Hongkong: Periplus Editions.

Krebs, C. J. (1999). Ecological Methodology (2 ed.). Philadelphia and San Francisco: Harper and Row.

Larson, H., \& Sparks, J. S. (2017). Butis butis. Retrieved April 14, 2020, from The IUCN Red List of Threatened 2017: https://www.iucnredlist.org/species/3381/58294204

Omar, S. B., Nur, M., Umar, M. T., Dahlan, M. A., \& Kune, S. (2015). Nisbah Kelamin Dan Ukuran Pertama Kali Matang Gonad Ikan Endemik Pirik (Lagusia Micracanthus Bleeker, 1860) Di Sungai Pattunuang, Kabupaten Maros Dan Sungai Sanrego, 
Kabupaten Bone, Sulawesi Selatan . Seminar Nasional Tahunan XII Hasil Penelitian Perikanan dan Kelautan (pp. 73-81). Yogyakarta: Universitas Gadjah Mada.

Persada, L. G., Utami, E., \& Rosalina, D. (2016). Aspek Reproduksi Ikan Kurisi (Nemipterus furcosus) yang Didaratkan di Pelabuhan Perikanan Nusantara Sungailiat (Studi Kasus: Hasil Tangkapan Bulan Maret sampai Mei 2015). Akuatik: Jurnal Sumberdaya Perairan, 10(2), 46-54.

Probo, B. (2013). Ikan Belosoh Ikan Hias Populer. Retrieved April 14, 2020, from Satu Harapan: $\quad$ http://www.satuharapan.com/read-detail/read/ikan-belosoh-ikan-hiaspopuler

Sari, Y. N. (2016). Jenis-Jenis Ikan di Sungai Boleleu Desa Sidomakmur Kecamatan Sipora Utara Kabupaten Kepulauan Mentawai. Padang: Program Studi Pendidikan Biologi STKIP PGRI Sumatera Barat.

Sitorus , H., Lesmana, I., \& Tarigan , R. (2017). Relationship of mangrove density with fish diversity inthe waters of mangrove area at Lubuk Kertang Village, Langkat District of North Sumatera. International Journal of Fisheries and Aquatic Studies, 5(5), 266271.

Tjakrawidjaja, A. H., \& Haryono. (2001). Studi Populasi Ikan Koloso (Scleropages jardinii) Di rawa Pomo Kecamatan Citak Mitak, Kabupaten Merauke, Papua. Berita Biologi, 5(4), 357-364. 